Marco Bagliacca · Alberto Profumo

Cecilia Ambrogi · Roberto Leotta · Gisella Paci

\title{
Egg-laying differences in two grey partridge (Perdix perdix L.) lines subject to different breeding technology: artificial egg hatch or mother egg hatch
}

Received: 7 April 2004 / Accepted: 28 July 2004 / Published online: 7 September 2004

(C) Springer-Verlag 2004

\begin{abstract}
Artificial breeding bypasses the effect of natural selection and, inevitably, subjects game birds to selection by breeding technology. For this reason, we evaluated whether different breeding technologies, carried out for six generations, were enough to differentiate two grey partridge lines. Two lines of grey partridges, obtained from the same population, were used: the animals of the line "broody" had been hatched directly by their own mothers for six generations; the animals of the line "incubator" had always been hatched in incubators from eggs laid by cage-reared grey partridges. Offspring from the two lines were reared under the same conditions and 2 years of production were monitored. Results showed that grey partridges of the "broody" line had a shorter and delayed laying period and, consequently, a lower egg production than the "incubator" line. In the first year of production, mean length of laying period 58 vs. 75 days, $p<0.01$; mean start of egg production through photostimulation: 61 vs. 42 days, $p<0.01$; mean number of eggs laid: 46 vs. $58, p<0.01$. In the second year: mean length of laying period, 63 vs. 66 days, $p<0.05$; mean start of first egg production through photostimulation: 51 vs. 45 days, $p<0.05$; mean number of eggs laid: 45 vs. $56, p<0.01$.
\end{abstract}

Keywords Grey partridge - Selection - Captive breeding $\cdot$ Incubation

\footnotetext{
M. Bagliacca $(\bowtie) \cdot$ A. Profumo $\cdot$ R. Leotta $\cdot$ G. Paci

Department of Animal Production,

College of Veterinary Medicine, V. le Piagge,

256100 Pisa, Italy

E-mail: mbagliac@vet.unipi.it

C. Ambrogi

Ministry of Agricultural and Forestry Politics,

Office of Lucca, V. le Cadorna, 155100 Lucca, Italy
}

\section{Introduction}

Artificial breeding bypasses the effects of natural selection and, inevitably, subjects game birds to selection by breeding technology. The main effects are due to the use of commercial diets which, by satisfying the partridge's every requirement, induces changes in gut morphology, and allows the survival of animals which would have died on poorer diets (Bagliacca et al. 1995; Mussa et al. 1997; Liukkonen et al. 1999). In addition, within a few generations, common rearing technologies change the physiology and anatomy of captive-reared grey partridges, which become heavier, with larger breast muscles and lighter hearts and livers than wild birds (Putaala et al. 1995; Millán et al. 2001). The use of artificial hatching also induces differential behaviour and survival between artificially reared and naturally born grey partridges (Dowell 1990; Lewis et al. 1998; Bagliacca et al. 1998, 1999). For this reason, we evaluated whether different breeding technologies, carried out continuously for six generations, were sufficient to differentiate two grey partridge lines from the point of view of reproduction.

\section{Materials and methods}

Two lines of grey partridges, obtained by the same population of Mediterranean grey partridges reared in the experimental breeding farm of the Italian Ministry of Agriculture - Castelnuovo Garfagnana-Tuscany were tested for 2 years.

During the 6 years before the start of the test, the birds of the line "broody" had been hatched directly by their own parents for six generations; the animals of the line "incubator", the most widespread captive-rearing technology, had always been hatched in incubators from eggs laid by the cage-reared parents. Every year, in December, the future reproducers had been chosen randomly between the chicks hatched from the eggs laid 
Fig. 1 Egg laying over 2 years: squares first year, "broody" line ; triangles first year,

"incubator" line; $\times$ second year, "broody" line; stars second year, "incubator" line

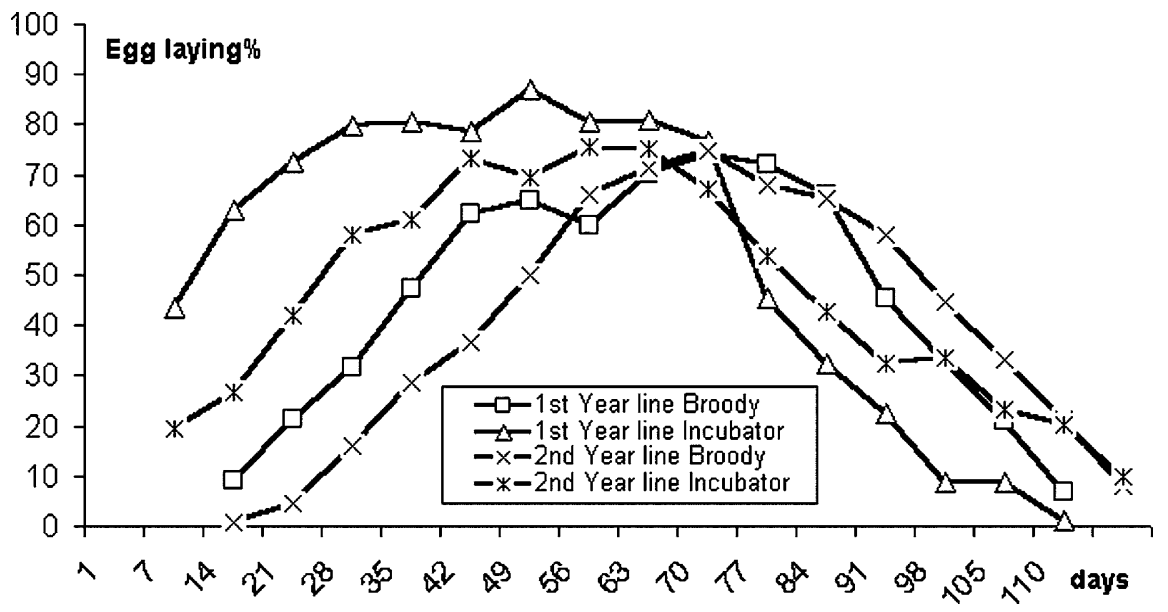

at start of the egg laying season (from the second hatch) or between the chicks reared and brooded by their own parents.

To reduce possible effects due to different imprinting/ training in the partridges submitted to the test and to evaluate only the effect of the selection carried out by the breeding technology during the previous six generations, week-old chicks were randomly selected from the two lines and reared under the same conditions (under artificial gas brooders) until December, when 27 pairs from each line were constituted by force pairing and bred in net floor cages $(0.5 \times 1.5 \times 0.3 \mathrm{~m})$. In spring of both years (February to May), the natural photoperiod was artificially extended (natural + artificial $=16 \mathrm{~L}: 8 \mathrm{D})$ to induce sexual development and reproduction(Lewis et al. 1998) and, during the laying periods, the eggs were collected twice a day and incubated weekly.

At the end of the first laying period (year 1), the pairs (each bird identified by a numbered leg ring) were transferred to a flying pen until the next December when the couples were again captured and paired in the laying cages, to repeat the test on the same animals for a second year of reproduction. During the laying periods, the birds were fed ad libitum with a commercial laying diet, while, during the rest period, the partridges were fed with a mixture of cereals and a commercial pellet for maintenance.

The number of eggs laid per couple were analysed by Wilcoxon/Kruskal-Wallis tests (rank sums); times (days from initiation of photostimulation to commencement of egg laying, days from initiation of photostimulation to end of the egg-laying period, and length of the egglaying period) were analysed by standard least squares; hatching percentages (fertility of incubated, hatchability of fertile, hatchability of incubated eggs) were analysed by chi square (Wilkinson 1988).

\section{Results}

The results (see Fig. 1) showed that in the first year of production the cage-bred grey partridges, coming from six generations of natural brooding, "broody" line (22 productive pairs) had a delayed and shorter laying period and, consequently, a lower egg production than the "incubator" line (24 productive pairs). Statistical analysis of performance (Table 1) revealed differences in the number of days between initiation of photostimulation and commencement of egg laying (mean: 60.7 vs. 42.1 days, $p<0.01$ ), egg-laying period (mean: 58.3 vs. 75.4 days, $p<0.01$ ) and number of eggs laid per pair (mean: 45.8 vs. $58.3, p<0.05$ ).

In the second year of production, 16 couples of the "broody" line and 20 couples of the "incubator" line remained in production. Five couples of the "broody" line were used to test the possibility of a partially natural production of day-old chicks after an initial period of cage production (Profumo et al. 2001), and six couples of the "broody" line and seven couples of the "incubator" line were lost either due to no production or death of one of the two birds. The results of the first year were confirmed: the laying period in the "broody" line was again shorter and delayed (mean length: 63.2 vs. 66.1 days, $p<0.05$; mean period from initiation of photostimulation to first egg production : 50.8 vs. 44.9 days, $p<0.05$;) and, again, the "broody" line showed a lower egg production than the "incubator" line (mean number of eggs laid: 45.4 vs. 55.6, $p<0.01$ ).

Incubation results showed a lower mean fertility and hatchability of the "broody" line compared to the "incubator" line eggs (fertility 70.5 vs. 85.5, $p<0.01$; hatchability of fertile 85.3 vs. $89.2, p<0.05$ ) but, in the second year, the differences between lines disappeared. The effect of the first reproduction year, however, influenced the performance over 2 years, so that the fertility in the "broody" line remained lower than in the "incubator" line $(p<0.01)$.

\section{Discussion}

The different responses in egg production and to photostimulation observed between the two groups of grey partridges, bred under the same conditions, 


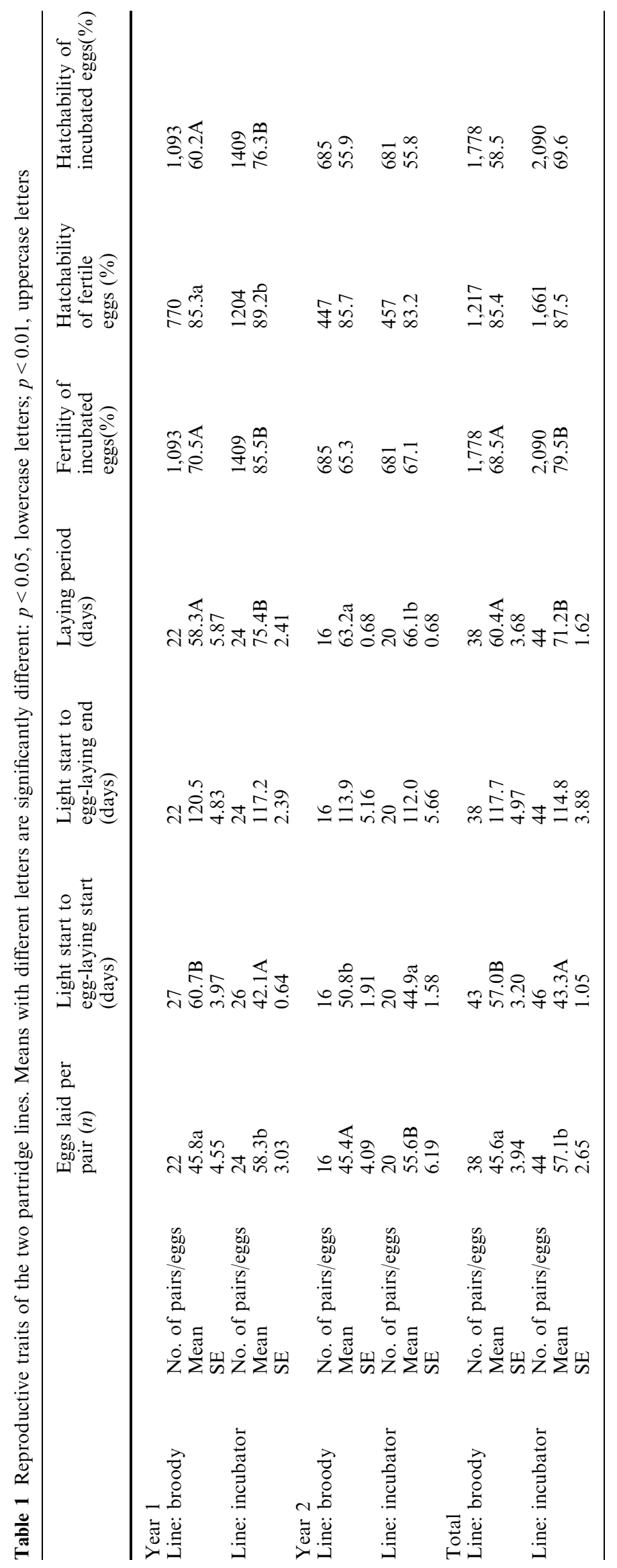


demonstrated a different genetic pattern and, consequently, the two groups can be considered two different strains (Thompson et al. 1992). The line selected by simple use of natural breeding technology was characterised by lower egg production and delayed commencement of egg laying; consequently, the offspring of this line seem better fitted for release in the wild than the offspring of the other line.

The reduced fertility in the "broody" line might have been due to a "genetically" restored, poor adaptability to unnatural breeding conditions: cage rearing. In fact, natural behaviour such as feeding, nest-site management and anti-predator behaviour were better in the "broody" line (Bagliacca et al. 1998).

Reduced hatching of fertile eggs, observed in the "broody" line during the first year of laying, due to higher embryonic mortality, might have been due to a similar poor adaptation of the eggs to the artificial hatch, but it might also have been due to a higher inbreeding related to the relatively small scope of the "broody" line (only 24 experimental pens each year).

A secondary result of the trial showed that grey partridges can be maintained in production for more than 1 year (at least 2 years). A second year of production can in fact be easily obtained, even if the number of eggs laid per couple during the second year is slightly reduced (no significant difference). The reduction of fertility, observed in the second year of production, however, influences the production of day-old chicks (from 28- to 25-day-old chicks per pair in the "broody" line and from 44- to 31-day-old chicks per pair in the "incubator" line).

Acknowledgements We are grateful to the Experimental Station of Bieri of the Italian Ministry of Agricultural and Forestry Politics where the experiments, complied with the Italian and European legislation on the animal welfare, were carried out.

\section{References}

Bagliacca M, Paci G, Marzoni M, Santilli F, Biagi G (1995) Effetto del diverso contenuto di fibra del mangime sullo sviluppo intestinale e sul profilo metabolico dei fagiani in accrescimento. Riv Avicoltura 65:33-39

Bagliacca M, Bennati L, Folliero M, Ambrogi C, Paci G (1998) Effetto della tecnica di allevamento sul comportamento antipredatorio della starna (Perdix perdix L.). Ann Fac Med Vet Univ Pisa 51:315-324

Bagliacca M, Profumo A, Paci G (1999) Effetto della tecnica di allevamento sulla reattività "fear" delle starne (Perdix perdix L.). Proc 53rd Congr SISVet, Montecatini (PT), pp 435-436

Dowell S (1990) Differential behaviour and survival of hand-reared and wild grey partridge in the United Kingdom. In: Church KE, Warner RE, Brady SJ (eds) Proc Perdix V: Grey partridge and ring-necked pheasant workshop, Kansas Department of Wildlife and Parks, Emporia, pp 230-241

Lewis PD, Morris TR (1998) A comparison of the effect of age at photostimulation on sexual maturity and egg production in domestic fowl, turkeys, partridges and quail. World Poultry Sci J 54:119-128

Liukkonen AT, Putaala A, Hissa R (1999) Does shifting from a commercial to a natural diet affect the nutritional status of hand-reared grey partridges (Perdix perdix)? Wildl Biol 5:147156

Millán J, Gortázar C, Villafuerte R (2001) Marked differences in the splanchnometry of farm-bred and wild red-legged partridges (Alectoris rufa L.). Poultry Sci 80:972-975

Mussa PP, Bergero D, Folliero M, Bassano B, Bagliacca M. (1997) Livello di fibra e digeribilità della dieta nel fagiano in crescita. Proc XII Congr Nazionale ASPA, Pisa, pp 345-346

Profumo A, Ambrogi C, Mani P, Paci G, Bagliacca M (2001) Cova diretta di starne (Perdix perdix L.) accasate in voliere a terra dal corteggiamento e da metà deposizione. Ann Fac Med Vet Univ Pisa 54:187-191

Putaala A, Hissa R (1995) Effects of hand-rearing on physiology and anatomy in the grey partridge. Wildl Biol 1:27-31

Thompson JD, Burger GV, Semel B, Ganshirt C (1992) Evaluation of the productivity of two strains of gray partridge. Poultry Sci 71:1400-1402

Wilkinson L (1988) SYSTAT: The system for statistics. Ed. Systat Inc. Evanston, Illinois, USA 